\title{
Trilhas das Cachoeiras de Taquaruçu (T0): mapeamento e caracterização
}

Tracks of Taquaruçu's Waterfalls (TO): mapping and characterization

Caminhos das Cascadas de Taquaruçu (TO): mapeo y caracterización http://dx.doi.org/10.18472/cvt.17n3.2017.1184

Stella Maria Carvalho de Melo 〈stella@ifpi.edu.br > Instituto Federal do Piauí (IFPI), Teresina, Piauí, Brasil.

Eveline Porto Sales Aguiar < evelineporto@ifce.edu.br > Instituto Federal do Ceará (IFCE), Fortaleza, Ceará, Brasil.

CRONOLOGIA DO PROCESSO EDITORIAL

Recebimento do artigo: 17-nov-2015

Aceite: 25-nov-2017

FORMATO PARA CITAÇÃO DESTE ARTIGO

MELO, S. M. C. de; AGUIAR, E. P. S. Trilhas das Cachoeiras de Taquaruçu - TO: mapeamento e caracterização. Caderno Virtual de Turismo. Rio de Janeiro, v. 17, n. 3, p. 96-112, dez. 2017.

REALIZAÇÃO

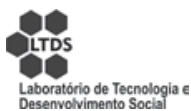

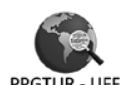

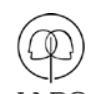

IABS
APOIO INSTITUCIONAL

COPPE

UFR]

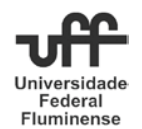

EDIÇÃO

EDITORA

PATROCÍNIO 


\section{RESUMO}

O presente artigo teve como objetivo verificar o processo de implantação das trilhas das principais cachoeiras de Taquaruçu - TO, analisando suas características e impactos para o meio ambiente e para a atividade turística. Foram pesquisadas as quatro cachoeiras mais visitadas e com trilhas bem delimitadas. Este trabalho teve como metodologia uma pesquisa exploratória com levantamento bibliográfico, observação informal e pesquisa de campo, com mapeamento das trilhas e a realização de uma entrevista semiestruturada com proprietários locais. Como resultado, constatou-se que todas as trilhas são lineares, possuem poucas lixeiras no seu percurso, vários pontos com raízes expostas, passagens e pontes feitas com tábuas de madeira, trechos com muitas pedras, árvores no meio da trilha, muitos galhos soltos e obstáculos, entre outros. Assim, concluiu-se que as trilhas precisam de uma manutenção mais efetiva para corrigir ou minimizar os problemas encontrados e que elas foram abertas sem um estudo prévio de impactos, o que pode acarretar danos no futuro, especialmente ao meio ambiente e à qualidade e segurança da visitação turística.

Palavras-chave: Trilha. Mapeamento. Meio ambiente.

\section{ABSTRACT}

This article aims to verify the implementation process of the tracks from Taquaruçu's (TO) main waterfalls, analyzing their characteristics and the impacts to the environment and to tourism. Therefore, were surveyed the four most visited waterfalls and with well-defined trails. As methodology, this study is a result of exploratory research with literature, informal observation and field research featured by mapping the trails and conducting a semi-structured interview with local owners. As an outcome, it was found that all tracks: are linear; have few dumps on their route, several points with exposed roots, passages and bridges made with wooden planks, stretches with lots of rocks, trees in the middle of the trail, many loose twigs and obstacles, among others. Thus, it was concluded that the paths need more effective maintenance to correct or minimize the problems encountered and that were opened without a previous study of impacts, which may cause future damages, especially to the environment and to the quality and safety of touristic visitation.

Keywords: Track. Mapping. Environment.

\section{RESUMEN}

Este artículo tiene como objetivo verificar el proceso de implementación de los caminos de las principales cascadas de Taquaruçu - TO, analizando sus características, los impactos al medio ambiente y al turismo. Fueron encuestadas las cuatro cascadas más visitadas y com caminhos bien definidos. Este estudio tuve una metodología de investigación exploratoria con la literatura, la observación informal y la investigación de campo con el mapeo de los caminos y la realización de una entrevista semiestructurada con los propietarios locales. Como resultado, se encontró que todas las pistas: son lineales; tienen pocos vertederos en su ruta, varios puntos con la vista las raíces, los pasajes y puentes hechos con tablones de madera, se extiende con mucha rocas, árboles en el medio de la pista, muchas ramas sueltas y obstáculos, entre otros. Por lo tanto, se concluyó que los caminos necesitan de un mantenimiento más eficaz para corregir o minimizar los problemas encontrados que se han abierto y sin un estudio previo de impacto que pueden causar daños en el futuro, especialmente para el medio ambiente y la calidad y seguridad de la visitación turística.

Palavras clave: Caminhos. Mapeo. Médio ambiente. 


\section{INTRODUÇÃO}

O turismo é uma atividade econômica que, se bem planejada, pode promover a proteção de ambientes naturais e estimular o desenvolvimento de localidades com potencial para tal. Para tanto, requer que a utilização desses espaços naturais seja bem ordenada, minimizando tanto quanto possível os seus impactos sobre o meio ambiente.

O turismo, quando praticado junto à natureza, tende a se massificar, gerando como consequência o aumento dos impactos negativos e a descaracterização dos atrativos naturais, como cachoeiras, praias, rios e lagos, tanto pela construção das infraestruturas de suporte e apoio para a atividade turística quanto pela própria atividade em si.

Entre os inúmeros impactos negativos do turismo, destacam-se: o uso excessivo dos recursos naturais, como água e o solo; pisoteio; assoreamento; a poluição sonora e do ar; depredação de construções ou áreas naturais; o aumento do acúmulo de resíduos sólidos e do lixo das destinações; poluição dos mares, rios e lagoas; destruição da fauna e da flora, entre outros.

Uma das formas de tentar minimizar esses impactos é planejando a implantação de trilhas, visando assegurar que esses efeitos negativos estarão dentro dos limites aceitáveis para a atividade turística. Assim, quando bem elaboradas, elas conseguem promover o contato mais direto entre o ser humano e a natureza, possibilitando conhecimento das espécies animais e vegetais, da história local, das relações ecológicas, do meio ambiente e sua proteção, constituindo instrumento pedagógico educacional, sendo um meio fundamental para a proteção ambiental.

Nesse sentido, destaca-se Taquaruçu, foco deste estudo, um distrito localizado a $32 \mathrm{~km}$ de Palmas, capital do estado do Tocantins, conforme Figura 1. Trata-se de um lugar onde algumas trilhas já foram implantadas, perfazendo mais de 80 cachoeiras catalogadas, impactando de forma positiva a prática do ecoturismo na localidade, gerando renda e desenvolvimento para a comunidade, além de atrair turistas de todo o estado.

Assim, o presente artigo tem por objetivo verificar o processo de implantação das trilhas das cachoeiras apropriadas para visitação em Taquaruçu, analisando características e impactos para o meio ambiente e para a atividade turística. 


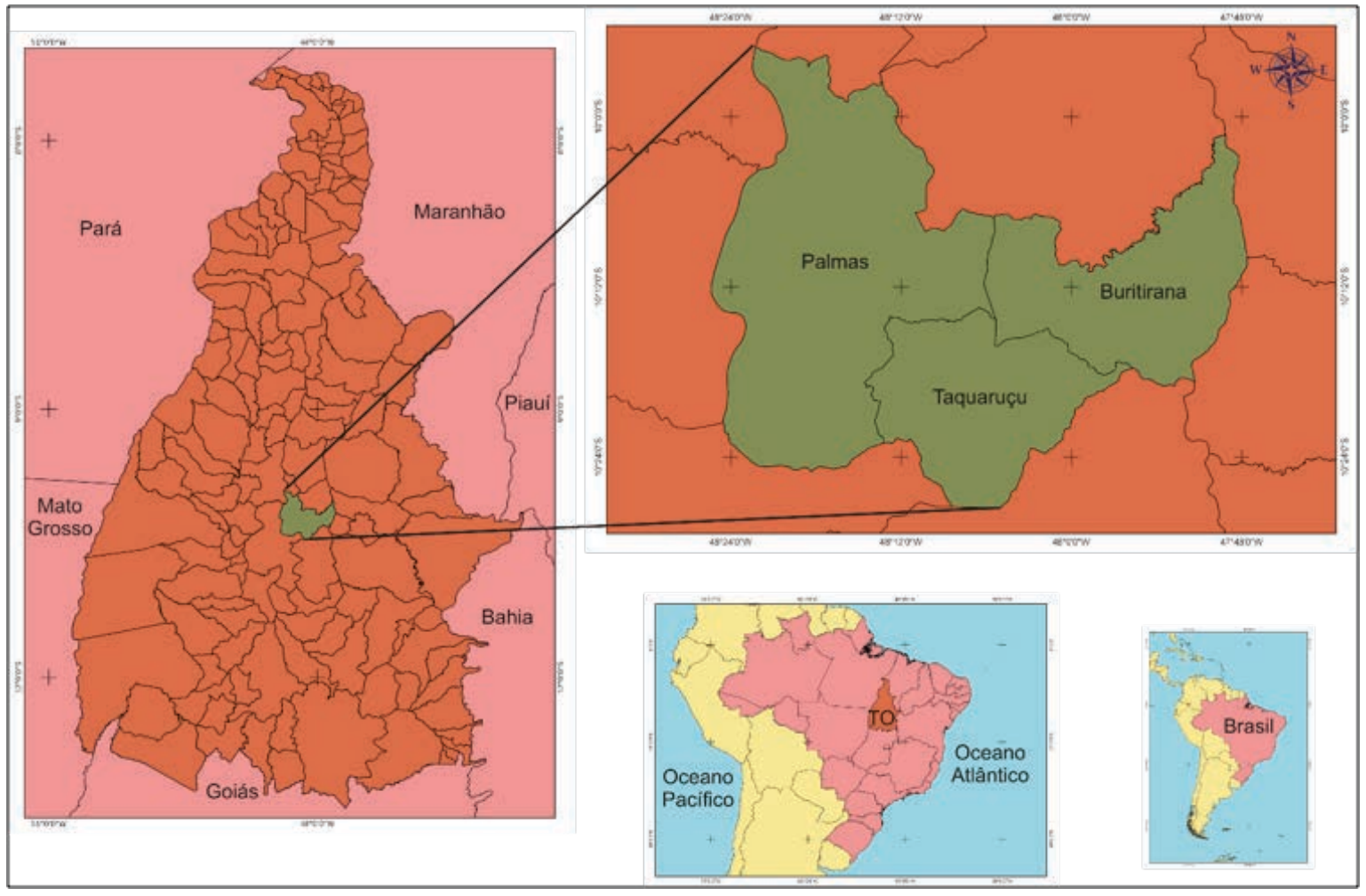

Figura 1 - Mapa da Localização de Taquaruçu - TO

Fonte: OLIVEIRA NETO (2017).

\section{MÉTODOS}

Esteartigo utilizou como metodologia a pesquisa exploratória, com levantamento bibliográfico, observação informal e pesquisa de campo. Para Dencker (1998, p. 156), "os estudos exploratórios compreendem, além do levantamento das fontes secundárias, o estudo de casos selecionados e a observação informal”. A autora afirma, ainda, que fazer pesquisa é observar a realidade, e muitos dados que o pesquisador precisa podem ser obtidos por meio da observação direta, por permitir o registro do comportamento no instante em que este ocorre (DENCKER, 1998).

Inicialmente, fez-se uma pesquisa bibliográfica sobre a temática, onde foram estudados diversos materiais relacionados com o planejamento, implantação e manejo de trilhas, e, em seguida, a coleta dos dados por meio da realização de entrevistas e pesquisa de campo em Taquaruçu - TO.

O distrito de Taquaruçu possui mais de 80 cachoeiras catalogadas, porém, poucas são abertas para visitação e, destas, apenas quatro possuem trilha bem delimitada. São elas: a Cachoeira da Roncadeira e a Cachoeira Escorrega Macaco, ambas dentro de uma mesma trilha e de propriedade particular, e a Cachoeira da Arara e Cachoeira da Meditação, ambas dentro de uma propriedade particular e meio de hospedagem.

A pesquisa de campo foi realizada durante os meses de agosto a outubro de 2015 e consistiu na observação direta da trilha e na realização de medições, com o uso de uma trena, para identificar largura da 
trilha e altura de degraus. O método envolveu, ainda, o mapeamento da trilha por meio de uma ferramenta geotecnológica, com o aplicativo Wikiloc, identificando o desenho da trilha, extensão e declividades.

Durante a pesquisa de campo, verificou-se também, por meio de análise da paisagem, as características físicas da trilha, bem como os impactos ambientais causados na região, com o registro fotográfico. Alguns dados coletados ao longo de toda a trilha foram: danos aos recursos naturais (quebra de galhos, inscrições em árvores, plantas pisoteadas fora da trilha, vandalismo e queimadas); danos à infraestrutura (pichação, remoção de estruturas e vandalismo); problemas de drenagem (empoçamentos, falta de sistema de drenagem; falta de manutenção nas canaletas/sistema de drenagem e erosão) e presença de lixo. Para essa análise, foram utilizados os mesmos critérios utilizados por Teixeira e Michelin (2013).

Foram realizadas ainda entrevistas, semiestruturadas, com proprietários dos locais onde ficam as cachoeiras para esclarecer algumas dúvidas sobre como se deu a implantação das trilhas. Após a coleta de dados, fez-se a tabulação e o processamento dos dados, de modo a obter subsídios suficientes para a compreensão da realidade investigada.

\section{Trilhas interpretativas}

As trilhas são caminhos previamente traçados que ligam um lugar a outro. Para o turismo, as trilhas unem lugares de interesse turístico. Segundo Vasconcellos (1998), trilha é uma palavra derivada do latim "tribulum", que significa caminho, rumo, direção.

As trilhas no Brasil ainda não recebem a atenção que deveriam por falta de manutenção periódica, influenciando até mesmo a segurança dos turistas. É possível encontrar no País muitas trilhas com bifurcações sem sinalização, trilhas que não levam a lugar de nenhum interesse, tomadas pelo mato e lixo e danificadas pelo vandalismo, contrariando o conceito de trilha turística.

De acordo com Murta e Goodey (2002, p. 36), a trilha "é uma rota, já existente ou planejada, que liga pontos de interesse em ambientes urbanos e naturais". Esses pontos são aqueles vistos pelo caminho que só podem ser percebidos por meio da interpretação que será dada na trilha.

Surgem daí as chamadas trilhas interpretativas, que, segundo Campos e Ferreira (2006), será o meio pelo qual as pessoas poderão desfrutar da natureza de forma planejada, segura e consciente, sendo um instrumento pedagógico e recreativo, ao passo que educa as pessoas a se comportarem em uma trilha, ao despertar para o contato e a proteção da natureza.

O principal objetivo das trilhas sempre foi suprir a necessidade de deslocamento. Porém, com o tempo, esse objetivo mudou, quando surgiram trilhas como um novo meio de contato com a natureza, sendo conhecidas como "trilhas de interpretação do ambiente natural", ou simplesmente trilhas interpretativas. A trilha é considerada interpretativa quando seus aspectos relevantes são transmitidos para os visitantes, com base em temas pré-definidos por meio de guias especializados, folhetos, painéis ou placas (PAGANI, 1996).

Entretanto, para que uma trilha seja bem-sucedida nesses objetivos, é necessário que seu planejamento e manejo sejam executados com sucesso. Isso deve ser feito tanto para trilhas novas quanto para as existentes, de forma a minimizar os impactos sobre o meio ambiente e aprimorar a experiência do visitante. Dessa maneira, Alcântara (2007, p. 39) afirma que: 
Ao se planejar um percurso de trilhas já existentes, além de prever os impactos negativos, deve-se valorar os perigos e riscos, planejar as rotas de fuga e acessos, definir planos de contingência. Isso, porque toda atividade na natureza envolve riscos: os subjetivos, que dependem dos conhecimentos e equipamentos dos praticantes, e os objetivos, que estão na natureza e não temos como evitar, os quais, porém, precisamos conhecê-los e minimizá-los, incluindo os possíveis danos resultantes. Identificando áreas prioritárias que necessitam de manutenção preventiva e/ou corretiva. Levando-se em conta que essas trilhas podem estar em área privada ou em áreas públicas, conservadas pelo Estado, é necessário respeitar os regulamentos existentes e colaborar com campanhas de manutenção e conservação.

Desse modo, não se pode abrir uma trilha sem um estudo detalhado da área, e nem abri-la sem realizar, posteriormente, o seu manejo (manutenção). As trilhas devem ser planejadas, buscando o aproveitamento máximo do local, sem comprometer a qualidade ambiental da área e a segurança dos visitantes. Yang et al. (2014) afirmam que, para conciliar as necessidades turísticas com conservação em áreas protegidas, é necessário fazer um planejamento de baixo impacto ambiental com trilhas atraentes.

Leung e Marion (1996) complementam que determinar o espaço mais adequado de configuração de trilhas é o primeiro passo importante no processo de planejamento. Essa configuração envolve a identificação de locais que minimizem os impactos ambientais, ao mesmo tempo que permitem que os turistas possam desfrutar da paisagem, permanecendo nas trilhas designadas, evitando que seus impactos se espalhem sobre áreas protegidas (YANG et al., 2014).

No entanto, segundo Yang et al. (2014), a maioria das trilhas em áreas protegidas é originalmente concebida para fins não recreativos, como agricultura, pecuária ou exploração madeireira. Para Leung e Marion (1996), embora sejam necessárias tais rotas, recursos de proteção e qualidade cênica raramente são motivos de preocupação quando elas são criadas. Consequentemente, o uso recreativo dessas trilhas frequentemente provoca problemas ambientais importantes, tais como a perda de vegetação, de acordo com Cole e Spildie (1998), a erosão do solo, conforme Leung e Marion (1999), modificação do comportamento dos animais, segundo Laiolo (2004), e fragmentação de habitat, de acordo com Potere et al. (2007).

Alcântara (2007) sugere que algumas etapas devem ser seguidas: realização de inventário, interpretação ambiental, identificação de impactos, delimitação da capacidade de carga, realização de obras ou compras de equipamentos e a sinalização. $\mathrm{Na} 1^{\text {a }}$ etapa do planejamento de uma trilha, é fundamental a realização de um inventário na área onde se pretende desenvolver atividades turísticas, mapeando as características locais do terreno, declividades, passagens de corpos-d’água, níveis de erosão, fragilidade ambiental, riscos e perigos existentes, bem como os diferentes elementos da geodiversidade e biodiversidade, entre outros.

O autor explica que, em seguida, na $2^{a}$ etapa deve-se elaborar a interpretação ambiental da trilha, destacando as características naturais e cênicas de modo criativo e não monótono, fazendo com que o visitante tenha o máximo de informações sobre o ambiente visitado. Essa interpretação deve ser apresentada por meio de mapas, panfletos, painéis e placas informativos, onde seu layout e diagramação devem combinar com as características da fauna e flora locais (ALCÂNTARA, 2007).

A $3^{a}$ etapa é a realização de um estudo sobre os impactos que a abertura da trilha pode provocar, como problemas no solo, na vegetação, na fauna e antrópicos (ocasionados pelo ser humano), e a $4^{\mathrm{a}}$ etapa é a realização do estudo de capacidade de carga local, analisando o número máximo de visitantes que a área pode suportar (ALCÂNTARA, 2007).

Ainda conforme o autor, as obras devem ser realizadas na etapa da implantação das trilhas e devem estar previstas no seu planejamento, devendo ser mantidas, alteradas ou refeitas na fase do manejo ou manutenção. Algumas obras podem ser feitas para corrigir problemas, tais como: drenagem, travessia 
de corpos-d’água e contenção da erosão do solo. A construção de canais de escoamento de água, pontes, passagens com blocos de pedra ou troncos de árvores, tablados, degraus ou paredes auxiliam a conter a erosão (ALCÂNTARA, 2007).

A última etapa, conforme Alcântara (2007), é a sinalização das trilhas, principalmente das trilhas autoguiadas (sem a presença do guia ou intérprete), com a marcação de tinta, fixação de placas ou totens e fitas.

Depois de planejada, a trilha deve ser implantada, o que constitui a fase onde é feita a sua abertura ou construção, de acordo com o que foi previsto no seu planejamento. E após a sua implantação, devese realizar a sua manutenção, periodicamente, conforme os procedimentos descritos no seu Plano de Manejo, a partir da identificação de impactos negativos ou problemas.

Quanto à classificação das trilhas, Andrade (2003) descreve que existem vários formatos de trilhas, como: circular, onde o ponto de partida é o mesmo do fim da trilha, sem repetir o percurso ou cruzar com visitantes; forma de oito: ideal para áreas limitadas, pois aumenta o uso desses espaços; linear: sua função é ligar o caminho principal a algum destino específico, onde o caminho de volta é igual ao de ida, havendo a possibilidade de cruzar com visitantes; atalho: onde seu início e fim situam-se em pontos diferentes da trilha.

Para Andrade (2003) as trilhas podem ser avaliadas em diferentes graus de dificuldade (leve, moderada ou pesada), levando em consideração a extensão do percurso, características do relevo, sinalização e outros. Essa classificação é bastante subjetiva, pois depende também da bagagem levada pelo visitante e do seu nível de condicionamento físico.

Conforme Lemos (1996), trilhas interpretativas são divididas em dois tipos: a guiada e a autoguiada. As trilhas guiadas são aquelas que requerem a presença de um intérprete ou guia, que acompanha os visitantes na caminhada, levando-os a observar, sentir, experimentar, refletir e questionar o ambiente, fazendo com que os visitantes usem os sentidos.

Nesse tipo de trilha, o visitante pode obter respostas às suas dúvidas com o intérprete, pois ele está presente para respondê-lo; há um controle mais eficaz da integridade do patrimônio, diminuindo o risco de degradar o ambiente; e o programa é adaptável ao usuário. Porém, as trilhas guiadas também têm desvantagens, como: a qualidade da mensagem transmitida depende do conhecimento do guia; o visitante é obrigado a acompanhar o ritmo do guia; e os passeios têm de ser feitos com reduzido número de pessoas.

As trilhas autoguiadas são aquelas com pontos de interesse marcados, onde o visitante, auxiliado por placas, painéis ou roteiros, constando de informações, desbrava o percurso sem o acompanhamento de um intérprete ou guia. Esse tipo de trilha permite receber maior número de visitantes, pois não há a obrigatoriedade de um guia acompanhá-los, e possibilita que o visitante percorra a trilha no seu próprio ritmo e conveniência. Entretanto, para manter as trilhas autoguiadas, o custo de manutenção pode ser alto, e ainda estão expostas ao vandalismo. Outra desvantagem é que, como não há a presença do intérprete, não se dispõe de uma pessoa para responder às perguntas imediatamente (LEMOS, 1996).

Lemos (1996) ainda faz uma divisão nas trilhas guiadas: natural geral, em que o guia percorre um caminho de um ponto de partida até o ponto final, sem estruturar atividades fixas; natural temática, em que o intérprete fixa as paradas com antecedência, dando maior coerência ao passeio; específica, que objetiva satisfazer interesses dos visitantes, como a observação de aves, por exemplo. 
Em relação às trilhas autoguiadas, Lemos (1996) subdivide em: temática, que tem a finalidade de interpretar um tema coerente à trilha; "miscelânea", que objetiva interpretar vários aspectos, mas sem tentar estabelecer uma relação entre eles; natural, que tem a finalidade de identificar as características naturais do local por meio de placas.

Portanto, as trilhas têm um papel fundamental na proteção da natureza e na aproximação do ser humano com o ambiente natural. Percebe-se, então, que não basta denominar um lugar como trilha para que ele possa ser considerado, de fato, uma trilha, uma vez que, para caracterizá-lo como tal, exige-se planejamento, estudo das condições do local e implantação das trilhas com o menor impacto possível no ambiente.

\section{As Trilhas das Cachoeiras: características e mapeamento}

Taquaruçu localiza-se a $32 \mathrm{~km}$ da capital do estado do Tocantins, Brasil; é procurada por visitantes da região, devido à facilidade de acesso e à sua grande quantidade de cachoeiras catalogadas. Em 2001, foi criado um Polo Ecoturístico pela Prefeitura de Palmas, para melhor estruturar os atrativos locais.

Por meio do inventário realizado pelo Governo do Estado do Tocantins (ADTUR, 2011), aponta-se, na região de Taquaruçu, formação geológica composta de rocha arenítica, no entorno e nas quedas, com vegetação de cerrado densa e bem conservada.

A região está inserida na Área de Proteção Ambiental - APA Serra do Lajeado, destacando sua importância em um rico e variado ecossistema de elevado interesse biológico para manutenção de todo o ecossistema natural da região, que em toda sua extensão apresenta características ambientais de caatingas, cerrados e da floresta tropical úmida, com a presença de cerca de 138 espécies, entre aves, mamíferos e répteis (AMATUR, 2000).

Neste trabalho, pesquisou-se quatro trilhas que têm como atrativo principal a chegada a cachoeiras bastante visitadas em Taquaruçu: Cachoeira Escorrega Macaco e Cachoeira do Córrego Roncadeira, Cachoeira da Arara e Cachoeira da Meditação, conforme Figura 2.

As duas primeiras são: Cachoeira Escorrega Macaco e Cachoeira do Córrego Roncadeira, ambas formadas pela queda do Ribeirão Taquaruçu, com $50 \mathrm{~m}$ e $77 \mathrm{~m}$ de queda livre, respectivamente. Ambas formam piscinas naturais próprias para banho, que ficam com maior vazão durante o período das chuvas (novembro a março), mas que permanecem com água durante o ano todo. Essas cachoeiras estão localizadas em uma propriedade particular, com guarita e cobrança de ingresso para visitação.

As outras cachoeiras são: Cachoeira da Arara e Cachoeira da Meditação, ambas localizadas em uma propriedade particular, chamada de Fazenda Ecológica, que conta com hospedagem. As cachoeiras têm uma altura média de $35 \mathrm{~m}$ e $5 \mathrm{~m}$, respectivamente, e também permanecem cheias durante todo o ano. 


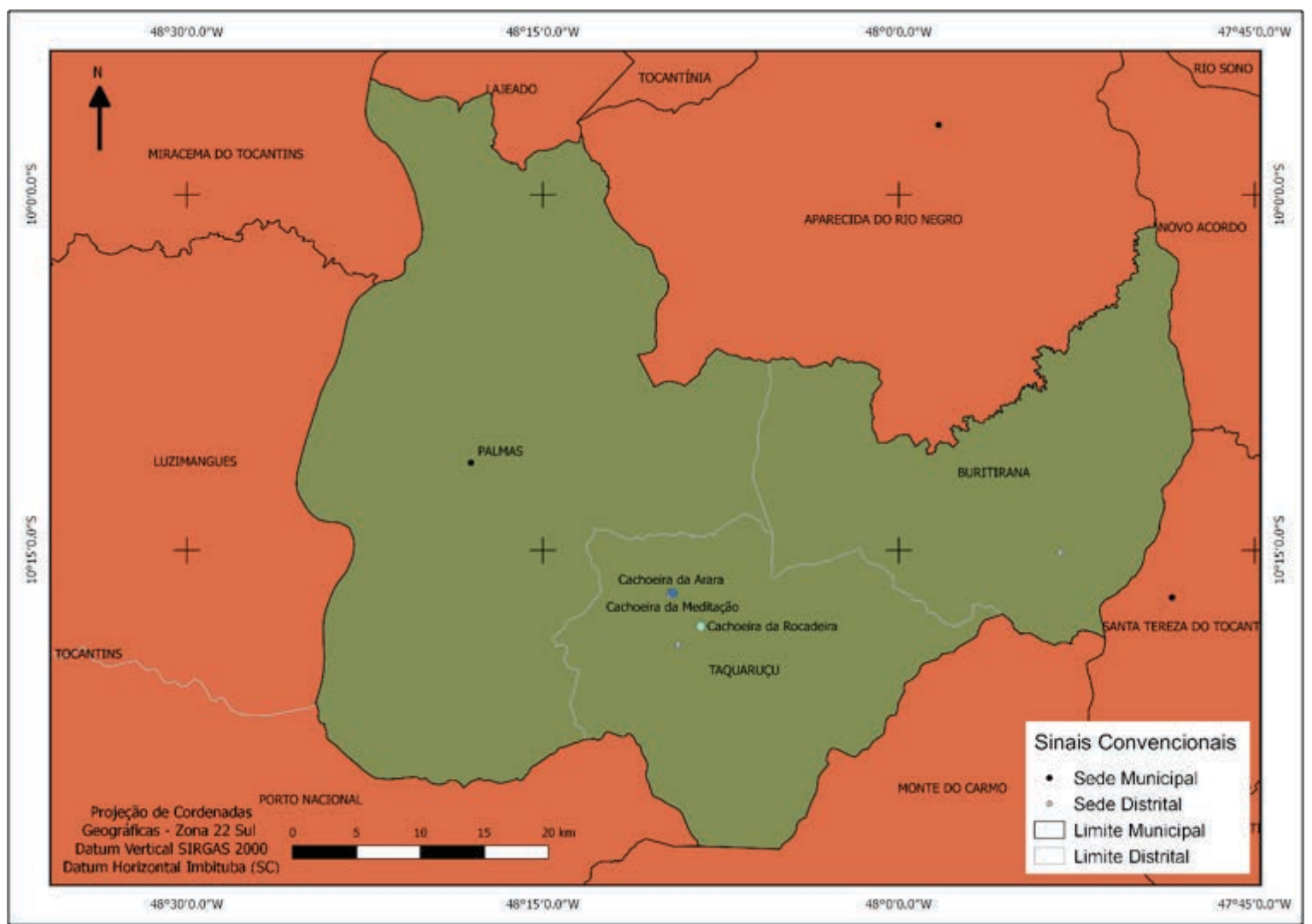

Figura 2 - Mapa da Localização das Cachoeiras, Taquaruçu - TO

Fonte: OLIVEIRA NETO (2017).

O acesso às cachoeiras Escorrega Macaco e do Córrego Roncadeira é feito a partir de uma única trilha principal, por onde os visitantes passam, com 1,6 km de extensão, levando a uma caminhada de aproximadamente 40 minutos, 15 minutos a mais do que o informado por uma placa no seu início. Existem trilhas paralelas devido a acessos ao córrego Taquaruçu, mas não são utilizadas pelos visitantes. A distância entre as duas cachoeiras é de 80 m, sendo a Escorrega Macaco a primeira a ser visitada.

Conforme observação e mapeamento dessa trilha, esta pode ser classificada como linear, mediante a classificação de Andrade (2003), visto que a sua função é ligar o caminho principal a um destino específico, no caso, as cachoeiras, onde o caminho de volta é igual ao de ida, havendo a possibilidade de cruzar com visitantes, de acordo com a Figura 3, que delineia esse formato. Constatou-se, também, que se trata de uma trilha de dificuldade moderada, levando em consideração a extensão do percurso, características do relevo, o qual tem muitos desníveis, pouca sinalização e obstáculos. Com esse mapeamento, verificou-se que a trilha tem um desnível de $127 \mathrm{~m}$ de altitude, tornando-a mais difícil para seus visitantes. 


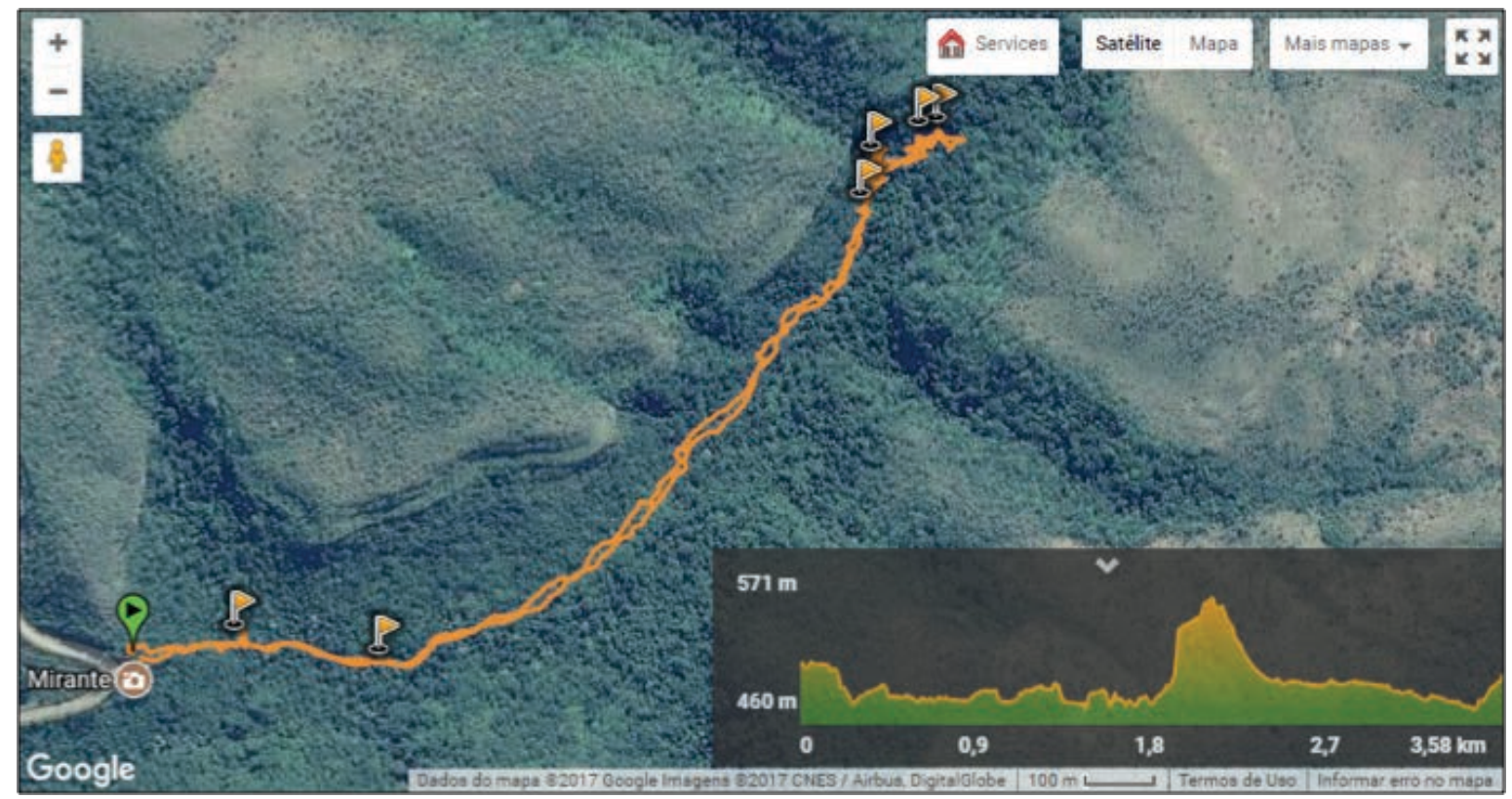

Figura 3 - Mapa da Trilha das Cachoeiras Roncadeira e Escorrega Macaco

Fonte: Wikiloc, agosto/2015 (WIKILOC, 2015C).

O acesso à Cachoeira da Arara é feito por uma trilha, também linear, com nível de dificuldade fácil, extensão de $730 \mathrm{~m}$ e desnível de $15 \mathrm{~m}$, com poucos obstáculos e algumas travessias de pontes, segundo dados do aplicativo Wikiloc (2015a), conforme Figura 4. Já a trilha da Cachoeira da Meditação tem $606 \mathrm{~m}$ de extensão, formato linear e desnível de 36 m, conforme Figura 5 (WIKILOC, 2015b).

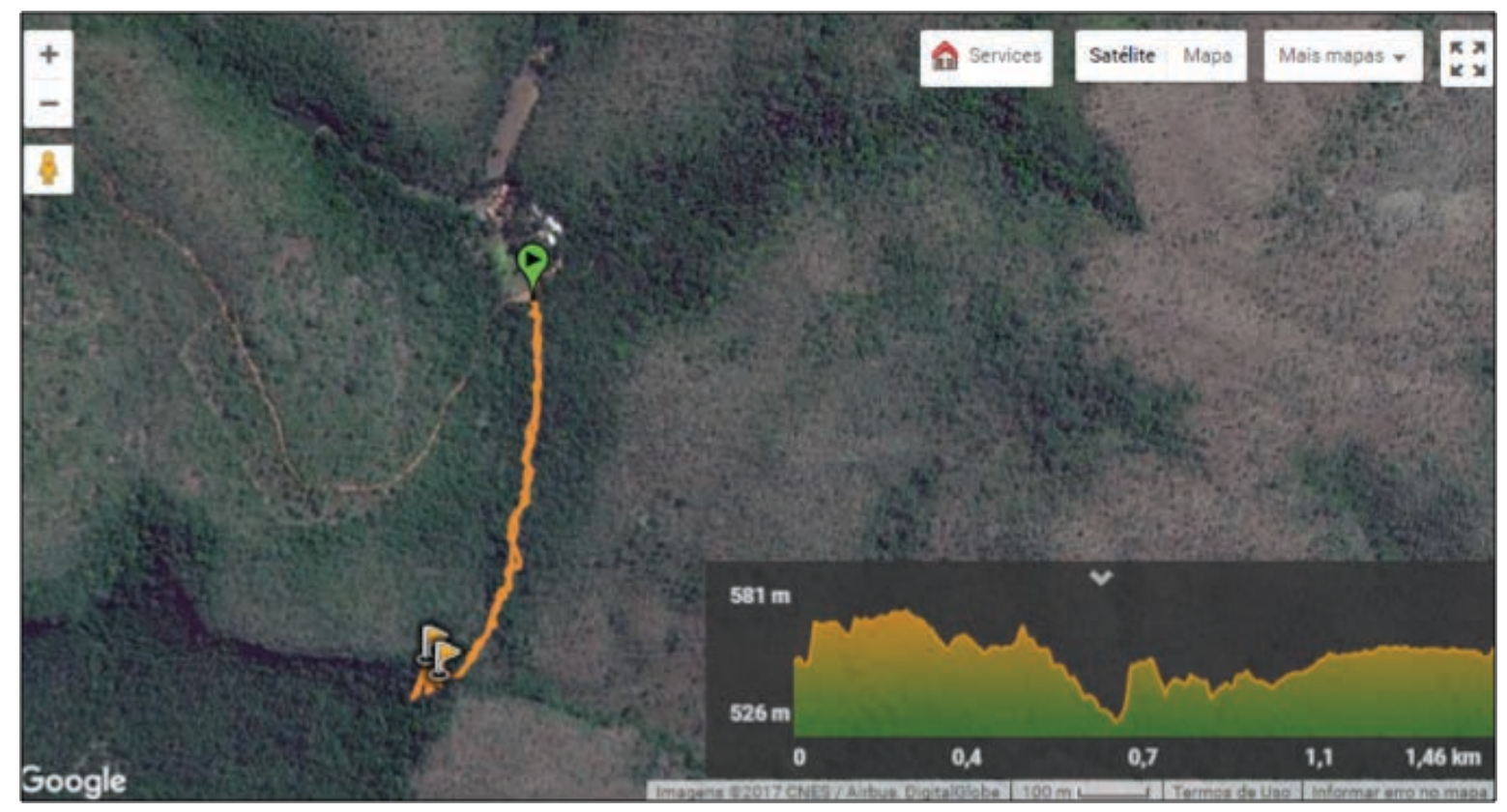

Figura 4 - Mapa da Trilha da Cachoeira da Arara

Fonte: Wikiloc, agosto/2015 (WIKILOC, 2015a). 


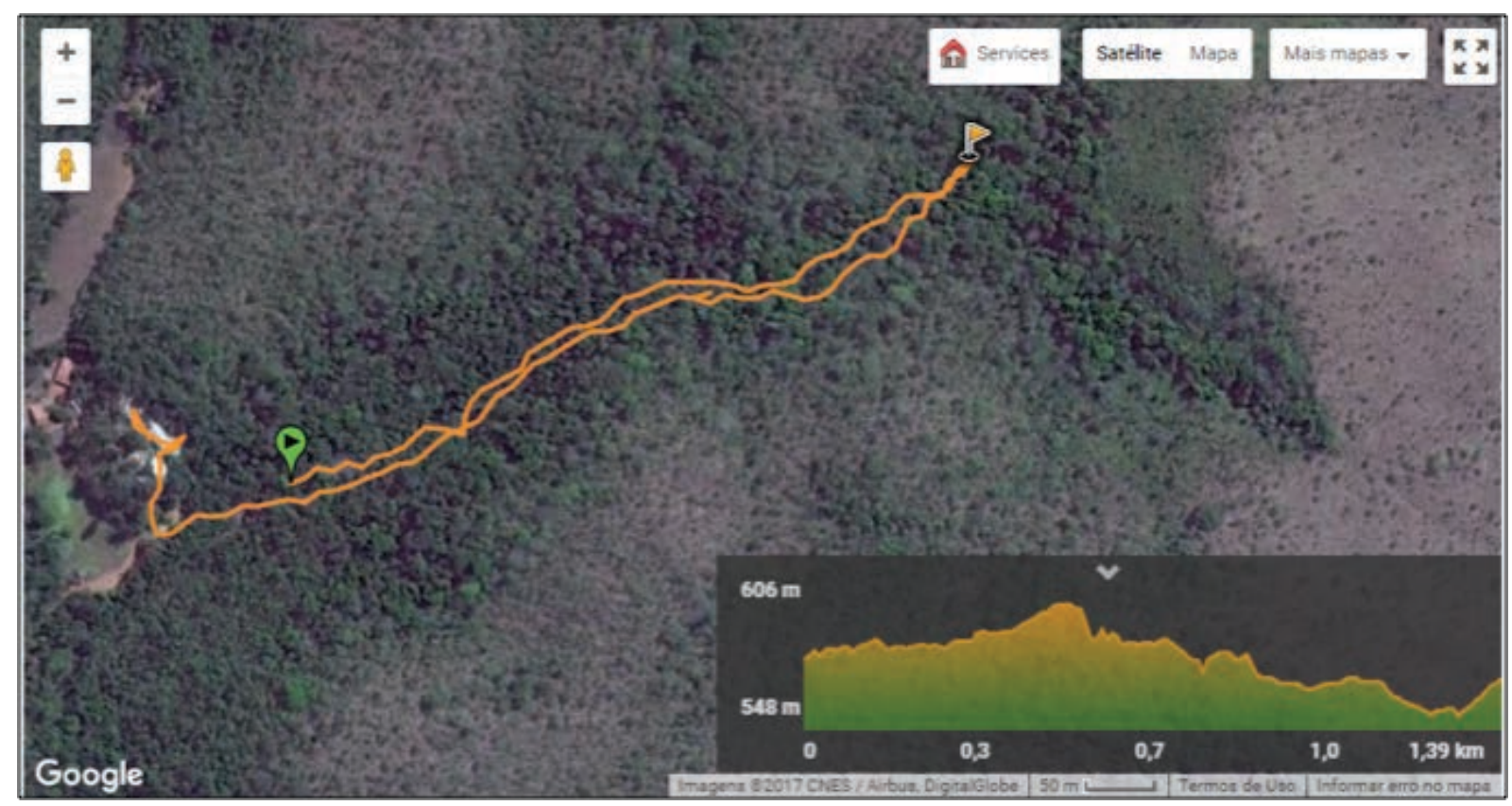

Figura 5 - Mapa da Trilha da Cachoeira da Meditação

Fonte: Wikiloc, agosto/2015 (WIKILOC, 2015C).

Durante a pesquisa de campo, com o uso de trena, foram feitas medições das alturas de degraus e largura da trilha que dá acesso às Cachoeiras da Roncadeira e Escorrega Macaco (Figura 6), em diversos pontos, e chegou-se ao seguinte resultado:

- A trilha não tem uma largura constante. Alguns trechos chegam a ter $146 \mathrm{~cm}$, enquanto outros até $49 \mathrm{~cm}$, o que é uma largura bem pequena para uma trilha linear, onde o mesmo percurso é feito para ir e voltar aos atrativos. A maioria das trilhas possui entre 90 a $95 \mathrm{~cm}$ de largura;

- Logo no início da trilha, existe um trecho com 143 degraus, que variam de $25 \mathrm{~cm}$ a $40 \mathrm{~cm}$ de altura, o que provoca um aumento da dificuldade da trilha;

- Passagens e pontes feitas com tábuas de madeira, em alguns casos, sem corrimões ou com corrimão apenas em um dos lados. Em alguns pontos, constatou-se que a altura média dos corrimões é inferior a 92 cm, que é o mínimo exigido pela norma NBR9050 da Associação Brasileira de Normas Técnicas - ABNT (2004);

- Trecho com travessia de troncos de árvores, com corrimão de cordas frouxas em apenas um dos lados. 

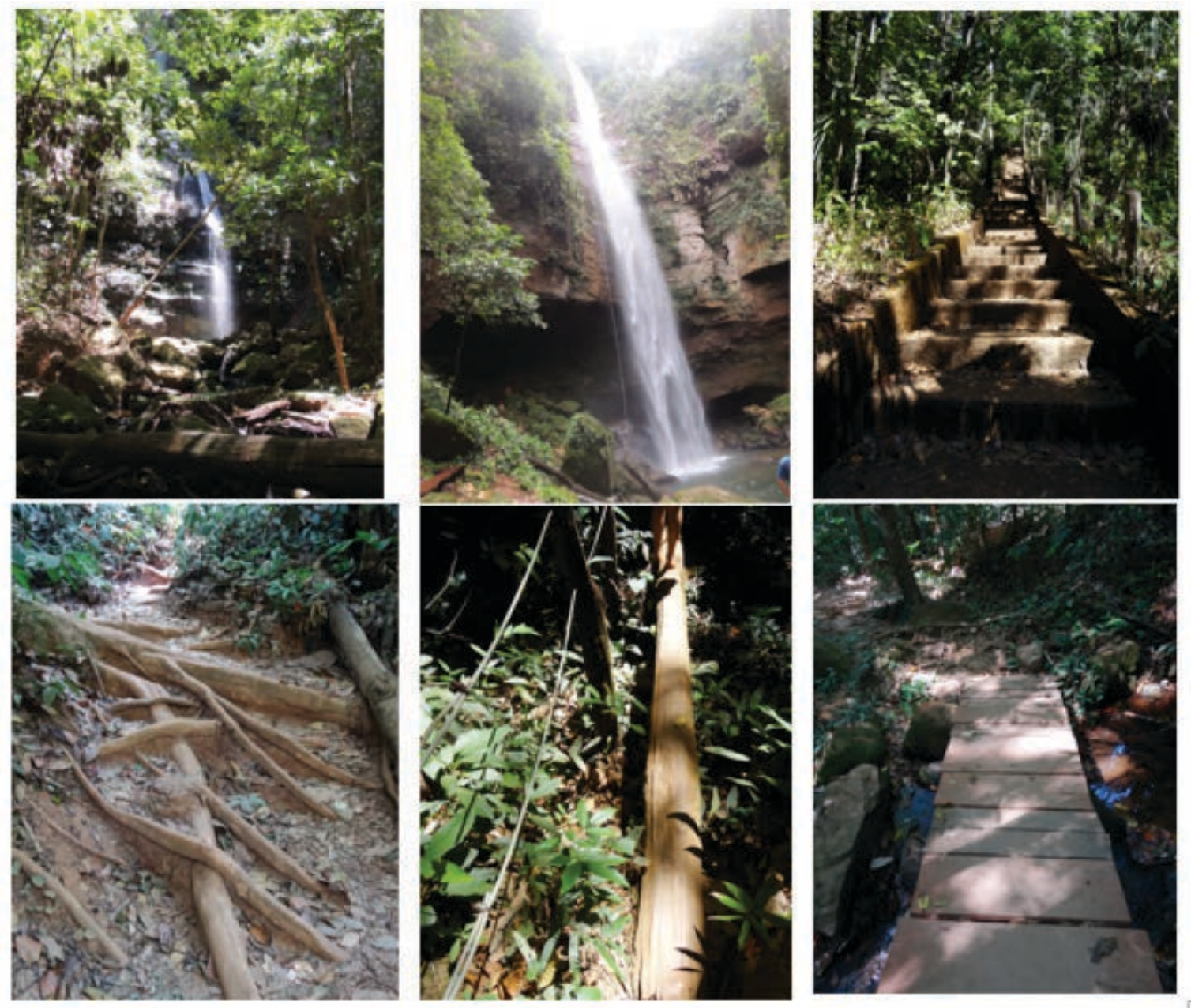

Figura 6 - Trilha das Cachoeiras Escorrega Macaco (A) e da Roncadeira (B) - degraus (C); raízes expostas (D); travessias (E) e (F)

Fonte: Elaborado pela autora.

Nas medições realizadas na trilha de acesso à Cachoeira da Arara (Figura 7), constatou-se que:

- A trilha não tem uma largura constante. Alguns trechos chegam a menos de $60 \mathrm{~cm}$ de largura, $\mathrm{e}$ outros com $150 \mathrm{~cm}$. A largura média é de $90 \mathrm{~cm}$;

- Existem cinco pontes de travessia na trilha, todas construídas com tábuas de madeira de $60 \mathrm{~cm}$ de largura e, em sua maioria, com apenas um corrimão na lateral para o visitante segurar. Esse apoio é feito com um arame envolto por um cano, com aproximadamente $1 \mathrm{~m}$ de altura;

- Há uma escada bem íngreme no fim da trilha, com corrimão de menos de $90 \mathrm{~cm}$ de altura, o que dificulta a sua descida e subida, podendo ocasionar acidentes.

Nas medições realizadas na trilha de acesso à Cachoeira da Meditação (Figura 7), constatou-se que:

- A trilha não tem uma largura constante. Alguns trechos chegam a menos de $60 \mathrm{~cm}$ de largura, $\mathrm{e}$ outros com $110 \mathrm{~cm}$. A largura média é de $70 \mathrm{~cm}$; 
- Existe uma ponte de travessia na trilha, construída com tábuas de madeira de $60 \mathrm{~cm}$ de largura, e com apenas um corrimão na lateral, de $90 \mathrm{~cm}$ de altura;

- Muitos trechos com a presença de lodo e musgos, tornando a trilha bastante escorregadia.
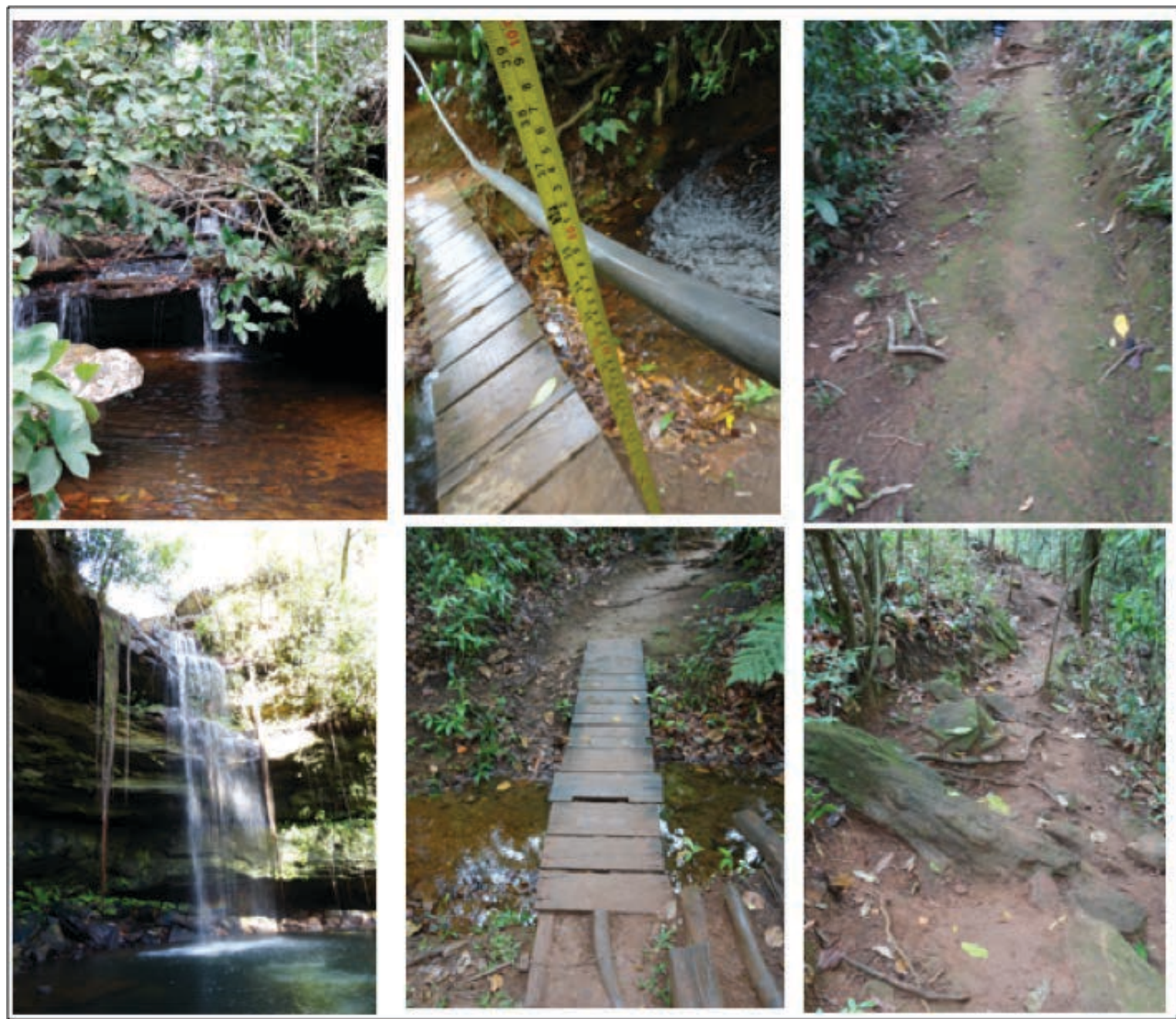

Figura 7 - Trilha das Cachoeiras da Meditação (A)/(B)/(C) e da Arara (D)/(E)/(F)

Fonte: Elaborado pela autora.

Todo acesso às trilhas é realizado a pé, o que auxilia na recuperação do ambiente natural. Como explica Andrade (2003), as trilhas deveriam ter apenas a largura que permitisse a passagem de uma pessoa de cada vez, isso reduziria o pisoteio e os impactos da visitação, que é o caso da trilha de acesso à Cachoeira da Meditação. Assim, ações de controle e manutenção são muito importantes, como a delimitação das bordas da trilha, que auxiliaria na diminuição desse alargamento. Lechner (2006) sugere que, para a demarcação das laterais da trilha, podem ser utilizados troncos de madeira ou rochas, diminuindo a ação erosiva da água.

Em todas as trilhas foi constatada, também, a existência de: poucas lixeiras em seu percurso e, no caso da Arara e Meditação, nenhuma; vários pontos com raízes expostas, o que dificulta a trilha e pode 
ocasionar acidentes; solo exposto em área sob influência direta de pisoteio, que não apresenta cobertura vegetal; trechos com muitas pedras, algumas delas soltas, o que pode ocasionar acidentes; árvores no meio da trilha; trilha "suja", ou seja, com a presença de muitos galhos soltos e com árvores e plantas com galhos que ultrapassam a área de caminhada, tornando-se obstáculos; trechos com muito lodo e musgos, o que torna a trilha escorregadia, principalmente na Trilha da Meditação.

Constatou-se, também, que nenhuma das trilhas é interpretativa, ou seja, não possuem placas de informação ao visitante. A existência delas tornaria a experiência muito mais enriquecedora e agradável, identificando as espécies vegetais, existentes no percurso, e animais da região.

A exposição das raízes das plantas, encontradas nas trilhas, é decorrente da erosão do solo, dificultando sua sustentação, além de poder provocar acidentes a seus visitantes. Esse é um problema grave e pode ser, em alguns casos, irreversível. Para Lobo e Simões (2009), a recuperação de áreas com erosão é extremamente onerosa e não garante a completa reabilitação do local.

Existem dois fatores de alteração decorrente do uso do solo: a sua compactação e erosão. O efeito do pisoteio produz um impacto mecânico direto, resultando na exposição das raízes das árvores, causando riscos de doenças e quedas dessas árvores, e na diminuição da capacidade de retenção de ar e absorção de água, alterando a capacidade do solo de sustentar a vida vegetal e animal associada (ANDRADE, 2003).

Averiguou-se que a vegetação do entorno das trilhas apresenta bom estado de conservação, e é possível encontrarmos até um bando de macacos na Trilha da Cachoeira da Roncadeira. Entretanto, foi constatada, também, a inexistência de placas de sinalização e placas interpretativas, que seriam necessárias, já que a trilha é autoguiada, ou seja, sem a presença de um guia ou condutor. A fixação das placas interpretativas proporcionaria uma melhor experiência do visitante com o meio ambiente, levando-o a conhecer as espécies da fauna e flora que encontra no caminho.

Foi averiguado que há risco de afogamento nas cachoeiras Roncadeira e da Arara, devido a sua alta profundidade, debaixo da queda-d'água (na primeira) e em toda sua piscina (na segunda), porém, não há orientação e sinalização para essa possibilidade/risco. Há, apenas, uma orientação quanto à proibição do uso de protetores solares e da produção de lixo na Roncadeira.

Apesar de nas trilhas da Roncadeira e do Escorrega Macaco haver poucas lixeiras, não se constatou a presença de latas, plásticos, papéis, entre outros, tampouco nas demais trilhas. Contudo, observou-se, em todas as trilhas e nas cachoeiras, que há um acúmulo de folhagens e galhos, que provocam um impacto visual e podem ocasionar insatisfação do visitante ao se deparar com a imagem de um local sujo.

Não se constatou, no período da visita de campo, problemas de drenagem da água, mas acredita-se que estes devem ocorrer no período das chuvas, pois não existem sistemas para escoamento da água em todas as trilhas, e como quase todos os percursos são ascendente e descendente, deve-se construir canais de drenagem ou bolsões de escoamento para reduzir ou prevenir esses problemas. Lobo e Simões (2009) afirmam que é comum verificar a presença de problemas de drenagem em trilhas mal planejadas, em que o problema existe independentemente do uso ou da sua intensidade, que pode ser seriamente agravado com o uso público.

Em entrevista com seus proprietários (comodatos) das cachoeiras Escorrega Macaco e da Roncadeira, o controle de fluxo de visitantes e a sua abertura tiveram início no ano 2001, sem um estudo prévio dos impactos. Isso significa que não foram realizadas todas as etapas necessárias para a abertura de trilhas, 
descritas por Alcântara (2007), que são: a realização de inventário, interpretação ambiental, identificação de impactos, delimitação da capacidade de carga, realização de obras ou compras de equipamentos e a sinalização. Somente foram feitas a abertura dos caminhos e adaptações para a passagem de pessoas. Só existem placas no início da trilha e duas próximas às cachoeiras.

Apesar de se ter controle do número de visitantes nesses locais, não é feita uma tabulação dessa lista para se ter ao certo o número de visitantes por dia e sua origem. De acordo com um estudo de capacidade de carga, realizado pela Prefeitura de Palmas, o local pode receber, no máximo, 600 visitantes/dia (ADTUR, 2011).

Já os proprietários da Fazenda Ecológica afirmaram que não têm controle do número de visitantes, e que as trilhas foram abertas há mais de 15 anos, também sem nenhum estudo prévio, e que em um feriado bastante movimentado chegaram a receber cerca de 100 visitantes/dia.

Ambos os proprietários afirmaram, ainda, que: têm poucos recursos e não possuem um orçamento próprio (para melhoria estética, da infraestrutura e condições de acesso da trilha); não existe Plano de Manejo das trilhas; não pretendem criar trilhas interpretativas; pretendem melhorar a manutenção das trilhas; não há previsão de adaptar as trilhas, embora existam subidas muito íngremes que impossibilitam a visitação de deficientes e idosos.

Assim, percebe-se que a falta de manutenção das trilhas pode causar acidentes em alguns trechos. Portanto, é fundamental que seja feita uma vistoria em todas as trilhas para identificar pontos problemáticos e corrigi-los ou minimizá-los.

\section{CONSIDERAÇÕES FINAIS}

Para se chegar a um atrativo turístico, não basta apenas abrir caminhos, criando trilhas. Estas devem ser interpretativas para informar características locais aos visitantes e também orientá-los. As trilhas interpretativas não visam buscar um simples contato com a natureza, mas promover também a sustentabilidade.

Trilhas em ambientes naturais, quando bem implantadas, fortalecem não só a atividade turística, mas também a conservação desses ambientes e de seus atrativos, por meio da informação e orientação aos visitantes, que transformam a postura do visitante e da comunidade local perante a natureza, gerando consciência ambiental quanto à proteção do meio ambiente.

Este estudo atendeu ao objetivo proposto de verificar o processo de implantação das trilhas das principais cachoeiras utilizadas para visitação em Taquaruçu - TO, analisando características e impactos para o meio ambiente e para a atividade turística. Como características, percebeu-se que as trilhas que levam às cachoeiras Escorrega Macaco, Roncadeira, Arara e Meditação têm formato linear, com grau de dificuldade fácil a moderado, devido a seus inúmeros degraus e obstáculos, sejam eles naturais ou não. Concluiu-se, também, que as trilhas não são interpretativas, apesar de serem autoguiadas, pois não contêm informações que possam aproximar o visitante ao meio ambiente local.

Os impactos identificados como ambientais e turísticos relacionaram-se com: ausência de placas informativas e interpretativas; trechos com travessias de troncos, sem a devida segurança ao visitante; 
trechos com árvores no meio e galhos sob a trilha; trechos com pontos de erosão, comprovados pela exposição de raízes; trechos com largura muito pequena, entre outros.

Averiguou-se que não há plano de manejo e que as trilhas foram abertas sem um estudo prévio de impactos, o que pode acarretar sérios problemas no futuro, principalmente ao meio ambiente local e à qualidade e segurança da visitação turística.

Em trilhas especialmente turísticas faz-se necessário examinar os benefícios que o investimento adequado, principalmente em sinalização, pode trazer, visto que esta deve ser coerente, promovendo e tornando mais aprazível o passeio do visitante, apreciando os atrativos turísticos existentes e promovendo a educação ambiental.

Portanto, com base nesse diagnóstico da trilha, os proprietários devem analisar que pontos poderiam ser melhorados e como minimizar os problemas encontrados, visando à conservação do ambiente natural e à sustentabilidade da atividade. Como, por exemplo: a fixação de placas interpretativas com informações sobre a fauna e a flora locais, bem como dos aspectos do meio físico (geodiversidade), aproximando o visitante ao meio ambiente local, transformando os caminhos em trilhas interpretativas; melhoria dos corrimões sobre as pontes, utilizando materiais mais resistentes; a colocação de passarelas nos pontos onde a erosão é maior; instalação de lixeiras em todo o percurso e a limpeza da trilha.

\section{REFERÊNCIAS}

ABNT. NBR 9050:2004 - Acessibilidade a edificações, mobiliário, espaços e equipamentos urbanos. Rio de Janeiro: ABNT, 2004.

ADTUR. Revelando Tocantins - turismo consciente, futuro sustentável. v. 1. Palmas, TO: Governo do Estado do Tocantins, 2011.

ALCÂNTARA, L. C. Trilhas interpretativas da natureza: planejamento, implantação e manejo. Monografia (Especialização). Especialização em Turismo e Desenvolvimento Sustentável. Universidade de Brasília, Centro de Excelência em Turismo. Brasília: UnB, 2007.

AMATUR. Diagnóstico turístico do distrito de Taquaruçu, Palmas - Tocantins. Palmas, TO: Prefeitura Municipal de Palmas, 2000.

ANDRADE, W. J. Implantação e manejo de trilhas. In: MITRAUD, S. C. (Org.). Manual de Ecoturismo de Base Comunitária: ferramentas para um planejamento responsável. Brasília: WWF Brasil, 2003.

CAMPOS, A. M. N.; FERREIRA, E. A. A Trilha Interpretativa da Vila do Americano - PA, Brasil: uma busca por conservação ambiental. Turismo em Análise, v. 17, n. 2, p. 155-169, novembro 2006.

COLE, D. N.; SPILDIE, D. R. Hiker, horse and llama trampling effects on native vegetation in Montana, USA. Journal of Environmental Management, v. 53, n. 1, p. 61-71, 1998.

DENCKER, A. F. M. Pesquisa em turismo: planejamento, métodos e técnicas. São Paulo: Futura, 1998.

LAIOLO, P. Diversity and structure of the bird community overwintering in the Himalayan subalpine zone: Is conservation compatible with tourism? Biological Conservation, v. 115, n. 2, p. 251-262, 2004. 
LECHNER, L. Planejamento, implantação e manejo de trilhas em Unidades de Conservação. Curitiba: Fundação O Boticário de Proteção à Natureza, 2006.

LEMOS, A. I. Turismo: impactos socioambientais. São Paulo: Hucitec, 1996.

LEUNG, Y. F.; MARION, J. L. Trail degradation as influenced by environmental factors: A state-ofknowledge review. Journal of Soil and Water Conservation, v. 51, n. 2, p. 130-136, 1996.

. Assessing trail conditions in protected areas: Application of a problem-assessment method in Great Smoky Mountains National Park, USA. Environmental Conservation, v. 26, n. 4, p. 270-279, 1999.

LOBO, A. C.; SIMÕES, L. L. Manual de Monitoramento e Gestão dos Impactos da Visitação em Unidades de Conservação. São Paulo: Secretaria de Meio Ambiente de São Paulo, 2009.

MURTA, S. M.; GOODEY, B. Interpretação do patrimônio para visitantes: um quadro conceitual. In: MURTA, S. M; ALBANO, C. (Org.). Interpretar o patrimônio: um exercício do olhar. Belo Horizonte: UFMG. p. 13-46, 2002.

OLIVEIRA NETO, T. I. de. Mapa da Localização das Cachoeiras, Taquaruçu - TO. 2017.

. Mapa da Localização de Taquaruçu - T0. 2017.

PAGANI, M. I. et al. As trilhas interpretativas da natureza e o ecoturismo. In: LEMOS, A. I. Impactos socioambientais. São Paulo: Hucitec, 1996.

POTERE, D. et al. Patterns in forest clearing along the Appalachian Trail Corridor. Photogrammetric Engineering \& Remote Sensing, v. 73, n. 7, p. 783-791, 2007.

TEIXEIRA, P. R.; MICHELIN, R. L. Monitoramento de impactos ambientais na trilha do Salto Ventoso, Farroupilha - RS. Revista Turismo - Visão e Ação - Eletrônica, v. 15, n. 2, p. 295-305 / mai-ago 2013.

VASCONCELLOS, J. M. O. Avaliação da visitação pública e da eficiência de diferentes tipos de trilhas interpretativas no Parque Estadual Pico do Marumbi e Reserva Natural Salto Morato - PR. Curitiba. 141fls. Tese (Doutorado em Ciências Florestais). Pós-Graduação em Engenharia Florestal, Universidade Federal do Paraná.1998.

WIKILOC. Trilha da Arara. Disponível em: 〈http://pt.wikiloc.com/wikiloc/view.do?id=11271217〉. Acesso em: 17 nov. 2015 a.

WIKILOC. Trilha da Meditação. Disponível em: 〈http://pt.wikiloc.com/wikiloc/view.do?id=11271235〉. Acesso em: 17 nov. 2015b.

WIKILOC. Trilha da Roncadeira. Disponível em: 〈http://pt.wikiloc.com/wikiloc/view.do?id=10619882〉. Acesso em: 17 set. $2015 \mathrm{C}$.

YANG, M. Y. et al. Nature conservation versus scenic quality: A GIS approach towards optimized tourist tracks in a protected area of northwest Yunnan, China. Journal of Mountain Science, v. 11, n. 1, p. $142-$ 155, 2014 . 